\title{
Incorporação de coque de petróleo em cerâmica vermelha
}

\section{(Incorporation of petroleum coke into red ceramic)}

\author{
L. A. de Freitas, S. N. Monteiro, R. Sánchez, C. M. F. Vieira \\ Laboratório de Materiais Avançados - LAMAV, Universidade Estadual do Norte Fluminense Darcy Ribeiro - UENF, \\ Av. Alberto Lamego 2000, Campos dos Goytacazes, RJ 28013-602 \\ luaredes-@hotmail.com,sergio.neves@ig.com.br,sanchez@uenf.br,vieira@uenf.br
}

\begin{abstract}
Resumo
Este trabalho tem por objetivo avaliar o efeito da incorporação do coque de petróleo nas propriedades físicas e mecânicas de cerâmica vermelha. Composições foram preparadas com $0 \%, 1 \%, 2 \%$ e $4 \%$ em peso de coque de petróleo incorporado numa massa argilosa caulinítica. Corpos-de-prova retangulares foram obtidos por extrusão para queima a $850{ }^{\circ} \mathrm{C}$ e $1050{ }^{\circ} \mathrm{C}$. As propriedades físicas e mecânicas determinadas foram: tensão de ruptura à flexão e absorção de água. A microestrutura das cerâmicas queimadas foi avaliada por microscopia ótica. Os resultados mostraram que o resíduo de coque de petróleo pode contribuir significativamente para a redução do consumo de energia durante a etapa de queima. Entretanto, incorporações devem ser realizadas em quantidades ao redor de $1 \%$ em peso para não prejudicar a absorção de água da cerâmica.
\end{abstract}

Palavras-chave: coque de petróleo, cerâmica vermelha, propriedades.

\begin{abstract}
This work has as its objective the evaluation of the effect of incorporation of petroleum coke in the physical and mechanical properties of red ceramic. Compositions were prepared with $0 \%, 1 \%, 2 \%$ and $4 \mathrm{wt} . \%$ of petroleum coke incorporated into a kaolinitic clayey body. Rectangular specimens were formed by extrusion to fire at $850{ }^{\circ} \mathrm{C}$ and 1050 ${ }^{\circ} \mathrm{C}$. The determined physical and mechanical properties were flexural rupture strength and water absorption. The microstructure of the fired ceramics was evaluated by optical microscopy. The results show that the petroleum coke waste can significantly contribute to reduce the energy consumption during the firing stage. However, incorporations must be done in amounts around $1 \mathrm{wt} . \%$ to avoid deleterious effect on the water absorption of the ceramic.
\end{abstract}

Keywords: petroleum coke, red ceramic, properties.

\section{INTRODUÇÃO}

Com a evolução dos processos industriais e o conseqüente surgimento de inúmeros produtos que rapidamente se tornaram de primeira necessidade, a atividade industrial adquiriu um caráter essencial na atualidade. Embora a sua importância seja indiscutível, a atividade industrial é responsável por gerar um número bastante elevado de resíduos, com diferenciadas formas e características. Diante deste fato, as indústrias se tornam uma grande fonte de geração de resíduos sólidos, líquidos e gasosos [1]. As indústrias mostram-se como vilãs na questão da poluição ambiental por dois fatores principais: o primeiro pelo acúmulo de matérias-primas e insumos, que envolve sérios riscos de contaminação por transporte e disposição inadequada; e o segundo pela ineficiência dos processos produtivos, o que necessariamente implica a geração de resíduos. Estes resíduos gerados no processo industrial se tornam um problema para as indústrias, fato que tem levado muitos órgãos municipais, associações, universidades e as próprias indústrias, a buscarem soluções viáveis para a questão dos resíduos, soluções estas que sejam criativas, práticas e operacionais, para tentar resolver ou minimizar tais problemas. A indústria do petróleo é um segmento que a cada ano, devido à necessidade da população mundial, aumenta sua produção. Dentre estes está inserido o coque de petróleo, resíduo com alto teor de carbono, poucas cinzas e contendo metais pesados, sendo produzido na etapa de refino do petróleo, denominada craqueamento.

A variabilidade natural das características das argilas e o emprego de técnicas de processamento relativamente simples para fabricação de cerâmica vermelha, como blocos de vedação e telhas, facilitam a incorporação de resíduos, melhorando a qualidade do produto final, além de contribuir para a redução do gasto energético, como é o caso do coque de petróleo, investigado neste trabalho. Por outro lado, materiais com elevadas quantidades de substâncias carbonáceas e/ou orgânicas, sejam resíduos ou não, tendem a aumentar a porosidade da cerâmica após queima [2-4]. Estes materiais geralmente não são incorporados em quantidades 
Tabela I - Composição química e poder calorífico do coque de petróleo.

[Table I-Chemical composition and calorific power of the petroleum coke.]

\begin{tabular}{ccc}
\hline Característica & Resultado & Unidade \\
\hline Enxofre total & 0,65 & $\%$ massa \\
Carbono fixo calculado & 87,15 & $\%$ massa \\
Cinzas & 0,07 & $\%$ massa \\
Material volátil & 12,79 & $\% \mathrm{massa}$ \\
Alumínio total & 18,20 & $\mathrm{mg} / \mathrm{kg}$ \\
Cálcio total & 12,5 & $\mathrm{mg} / \mathrm{kg}$ \\
Ferro total & 33,00 & $\mathrm{mg} / \mathrm{kg}$ \\
Potássio total & 5,30 & $\mathrm{mg} / \mathrm{kg}$ \\
Magnésio total & 2,00 & $\mathrm{mg} / \mathrm{kg}$ \\
Sódio total & 85,00 & $\mathrm{mg} / \mathrm{kg}$ \\
Níquel total & 99,00 & $\mathrm{mg} / \mathrm{kg}$ \\
Fósforo total & 1,30 & $\mathrm{mg} / \mathrm{kg}$ \\
Silício & 43,30 & $\mathrm{mg} / \mathrm{kg}$ \\
Titânio total & 0,30 & $\mathrm{mg} / \mathrm{kg}$ \\
Vanádio total & 59,00 & $\mathrm{mg} / \mathrm{kg}$ \\
Zinco total & 1,40 & $\mathrm{mg} / \mathrm{kg}$ \\
Poder calorífico superior & 8731,00 & $\mathrm{cal} / \mathrm{g}$ \\
Poder calorífico inferior & 8550,00 & $\mathrm{cal} / \mathrm{g}$ \\
\hline
\end{tabular}

maiores que $10 \%$ em peso [2]. Devido ao elevado poder calorífico ao redor de $31.000 \mathrm{~kJ} / \mathrm{kg}$, o coque de petróleo possibilita uma significativa economia de energia [2]. Os teores de incorporação deste resíduo em massas para a fabricação de blocos de vedação são sempre menores que $2,5 \% \mathrm{em}$ peso [5]. Nestes experimentos não ocorreram mudanças significativas na qualidade do produto final, exceto pela redução máxima de $15 \%$ na resistência mecânica sem, entretanto, comprometer sua aceitação. Este trabalho se propõe a investigar um teor de coque incorporado acima da quantidade máxima investigada. Neste sentido, tem por objetivo avaliar o efeito da incorporação de até $4 \%$ em peso de coque de petróleo nas propriedades físicas e mecânicas de uma cerâmica argilosa de forma que seja possível identificar a quantidade ideal para se obter o efeito benéfico da economia energética sem prejudicar a performance técnica da cerâmica.

\section{MATERIAIS E MÉTODOS}

Os materiais utilizados foram massa argilosa e coque verde de petróleo. A massa argilosa é constituída da mistura de duas argilas cauliníticas disponíveis no município de Campos dos Goytacazes, RJ, utilizada na produção de telhas e blocos de vedação. O coque utilizado na forma in natura é um resíduo proveniente do petróleo (parte sólida), obtido como material de tratamento térmico de derivados pesados. Sua composição possui hidrocarbonetos sólidos e carbono, que varia de 84 a 97\%. A Tabela I apresenta a composição química do coque de petróleo.

A morfologia das partículas do resíduo foi avaliada por microscopia ótica (MO) em um microscópio Tecnival CGA. A granulometria das matérias-primas foi avaliada pela combinação das técnicas de peneiramento e sedimentação de acordo com norma técnica da ABNT [6]. As análises termo-diferencial (ATD) e diferencial termo-gravimétrica (DTG) foram feitas em equipamento com módulo de análise simultâneo, TA Instr. SDT2960. A taxa de aquecimento foi $10{ }^{\circ} \mathrm{C} / \mathrm{min}$ ao ar. As composições investigadas correspondem à incorporação de coque de petróleo à massa argilosa nas seguintes quantidades: $0 \%, 1 \%, 2 \%$ e $4 \%$.

Corpos de prova retangulares foram conformados por extrusão nas dimensões $110 \times 25 \times 11 \mathrm{~mm}^{3}$ e queimados a $850{ }^{\circ} \mathrm{C}$ e $1050{ }^{\circ} \mathrm{C} / 180 \mathrm{~min}$. A taxa de aquecimento e resfriamento foi $2^{\circ} \mathrm{C} / \mathrm{min}$. Foram determinadas as seguintes propriedades: absorção de água [7] e tensão de ruptura à flexão em três pontos [8]. As amostras foram secas em estufa a $(110 \pm 5)^{\circ} \mathrm{C}$ até massa constante. Depois foram mantidas em água fervente durante $2 \mathrm{~h}$, resfriadas e, com o auxílio de um pano úmido, foram levemente enxugadas. As amostras foram pesadas e a absorção de água calculada conforme equação:

$$
\mathrm{AA}=100 \mathrm{x}\left(\frac{\mathrm{Mf}-\mathrm{Mi}}{\mathrm{Mi}}\right)
$$

na qual AA = absorção de água (\%), Mi = massa seca (g) e Mf = massa saturada $(\mathrm{g})$.

A estatística de Weibull [9] foi aplicada com um número mínimo de 11 amostras, e o módulo de Weibull $\mathrm{m}$ foi obtido da tangente da curva de $\ln \ln (1 / \mathrm{P})$ em função de $\ln \sigma$, conforme a equação:

$$
\ln \ln (1 / \mathrm{P})=\ln \mathrm{V}-\mathrm{m} \ln \sigma_{\mathrm{o}}+\mathrm{m} \ln \sigma
$$

na qual $\mathrm{P}=$ probabilidade de sobrevivência, $\mathrm{V}=$ volume, $\sigma_{\mathrm{o}}$ = parâmetro de ajuste da equação e $\sigma=$ tensão de ruptura à flexão.

A microestrutura das cerâmicas queimadas foi avaliada por microscopia óptica no mesmo equipamento descrito anteriormente.

\section{RESULTADOS E DISCUSSÃO}

A Fig. 1 apresenta a curva de distribuição de tamanho de partículas das matérias-primas. Aproximadamente 65\% das partículas do resíduo apresentam tamanho entre 0,01 e $1 \mathrm{~mm}$. Esta distribuição de tamanho das partículas do coque de petróleo é apropriada à incorporação em cerâmica vermelha, que geralmente apresenta partículas inferiores a 2-3 mm, associadas com o espaçamento usual dos rolos dos laminadores industriais. Além disso, as partículas finas propiciam uma combustão mais fácil e acarreta poros menores, reduzindo a possibilidade de decréscimo na resistência mecânica da cerâmica. Já a massa argilosa apresenta uma granulometria inferior ao resíduo. O teor 


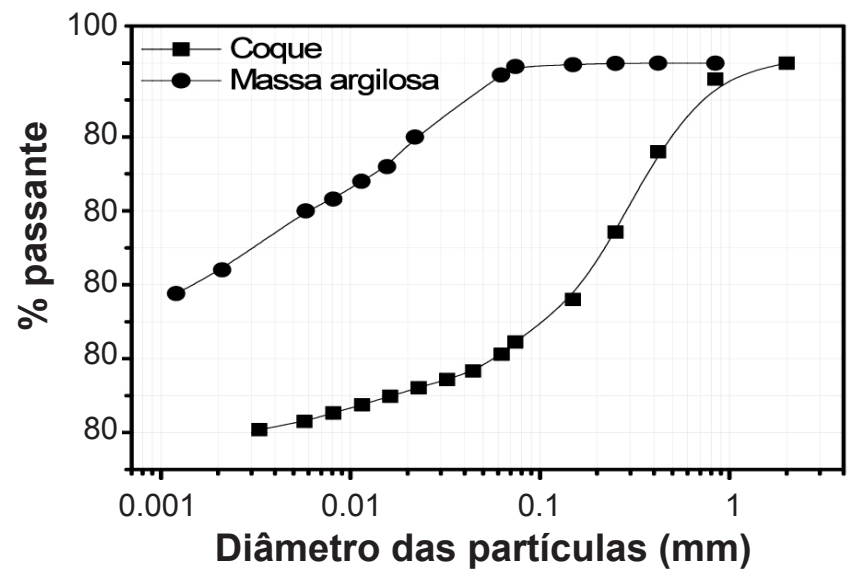

Figura 1: Curva de distribuição de tamanho de partícula das matérias-primas.

[Figure 1: Particle size distribution curve of the raw materials.]

da fração argila associada com tamanho de partícula inferior a 0,002 mm é 45\%. A fração argila confere à massa cerâmica plasticidade em mistura com água, possibilitando assim alcançar uma consistência plástica que possibilita conformar as peças por extrusão. O teor da fração silte, partículas com tamanhos compreendidos entre 0,002 e 0,02 mm, é $78 \%$. Já o teor da fração areia, que corresponde a partículas compreendidas entre 0,02 e $2 \mathrm{~mm}$, é $22 \%$.

A Fig. 2 mostra os aspectos morfológicos do coque de petróleo por meio de microscopia óptica. São observadas partículas brilhantes de formato irregular e tamanho variado. Esta morfologia está de acordo com o coque tipo esponja [10], considerado o mais comum em todo o mundo, atingindo cerca de $90 \%$ da produção mundial e é aquele produzido pelas unidades da Petrobrás. Nota-se também que o tamanho das partículas está de acordo com a curva de distribuição de partícula mostrada na figura anterior.

A Fig. 3 apresenta as curvas de ATD/TG/DTG do coque de petróleo. O coque de petróleo ganha $\sim 1,7 \%$ massa entre 250 e $350{ }^{\circ} \mathrm{C}$. Este ganho pode estar associado à oxidação de impurezas no coque. É observado um pico exotérmico a $567,8{ }^{\circ} \mathrm{C}$, onde acontece a queima de carbono fixo e de

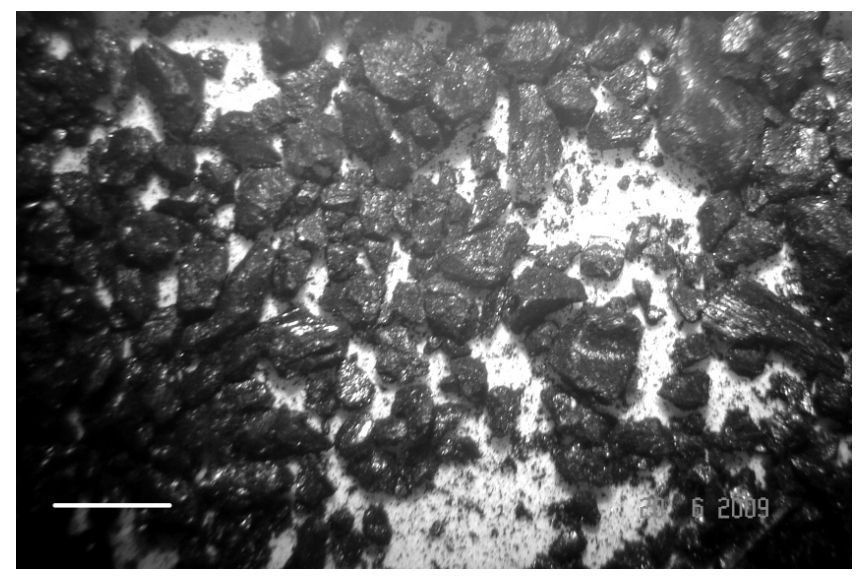

Figura 2: Micrografia de microscopia óptica do coque de petróleo. [Figure 2: Optical microscopy micrograph of the petroleum coke.]

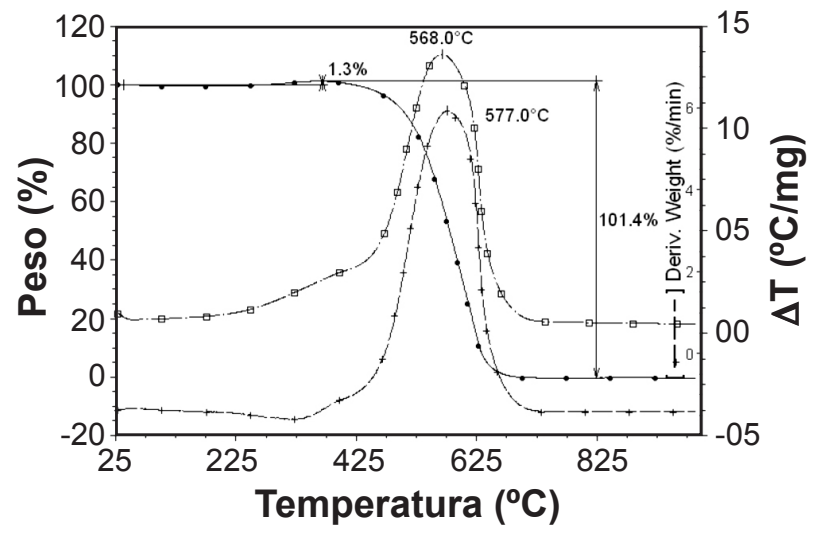

Figura 3: Curvas ATD/ATG/DTG do coque de petróleo. [Figure 3: DTA/TGA/DTG of the petroleum coke.]

material volátil, com liberação de calor. Esta característica do coque é a razão do principal benefício para seu uso no segmento de cerâmica vermelha: a economia de energia. Entretanto, a incorporação deste material pode aumentar a porosidade da cerâmica e consequientemente acarretar incremento da absorção de água e redução da resistência mecânica, prejudicando a qualidade final do produto. Esta avaliação é que vai ser apresentada a seguir.

A Fig. 4 apresenta o comportamento da absorção de água das cerâmicas em função da temperatura de queima. Com o aumento da temperatura ocorre uma redução significativa da absorção de água. Já a incorporação de coque até $1 \%$ praticamente não altera a absorção de água da cerâmica. Já incorporações em maiores quantidades tendem a aumentar a absorção de água da cerâmica, sobretudo a $1050{ }^{\circ} \mathrm{C}$ em quantidades superiores a $1 \%$. Conforme mencionado anteriormente, o aumento da absorção de água da cerâmica está associado com o aparecimento de porosidade aberta em função da queima do carbono e dos hidrocarbonetos presentes no resíduo.

As Figs. 5 a 8 apresentam a tensão de ruptura à flexão das composições estudadas por meio do diagrama de Weibull. Nota-se que o coeficiente de correlação linear, $\mathrm{R}$, apresenta valores bastante significativos. Pode ser

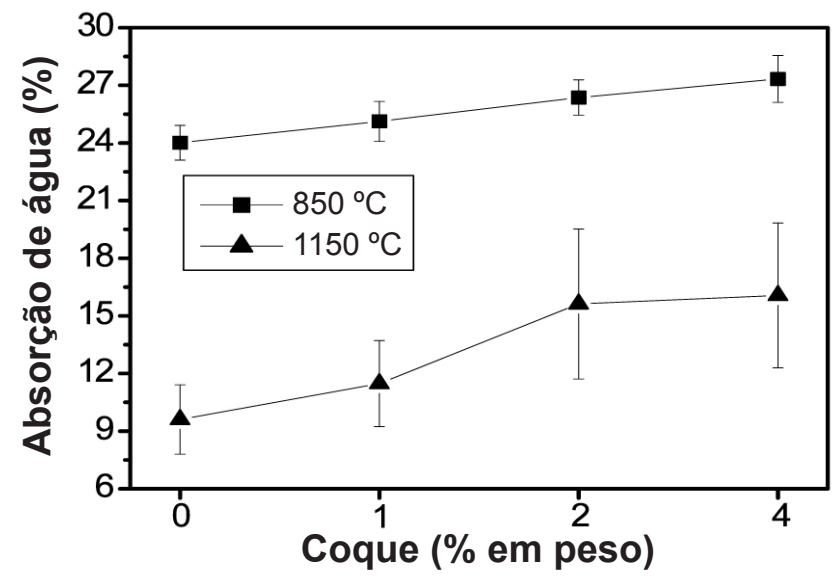

Figura 4: Absorção de água das composições.

[Figure 4: Water absorption of the compositions.] 


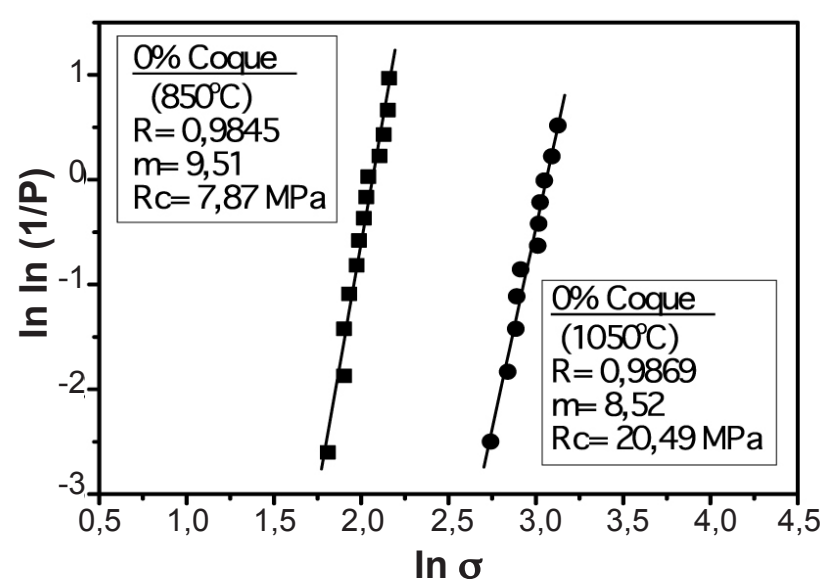

Figura 5: Diagrama de Weibull da composição sem coque de petróleo.

[Figure 5: Weibull diagram of the composition without petroleum coke.]

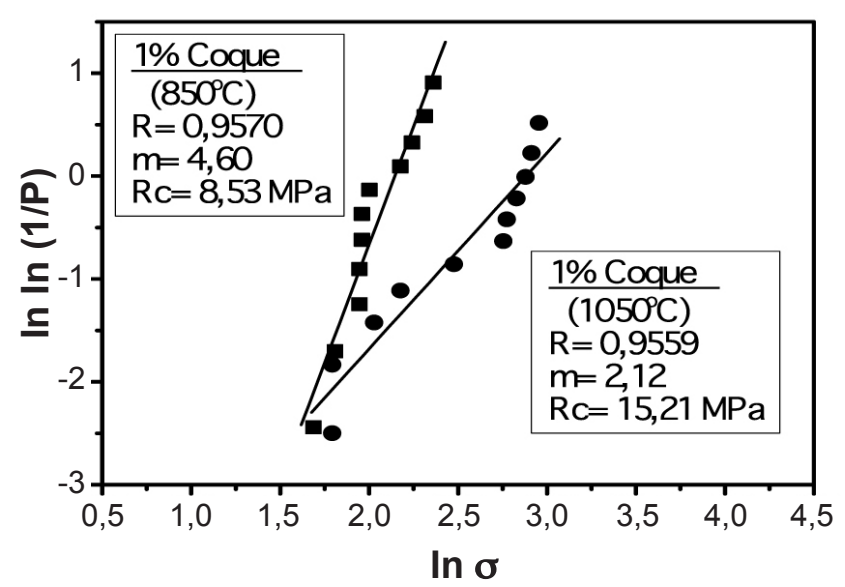

Figura 6: Diagrama de Weibull da composição com $1 \%$ em peso de coque de petróleo.

[Figure 6: Weibull diagram of the composition with 1wt.\% of petroleum coke.]

observado ainda que ocorre um aumento da resistência característica das cerâmicas, Rc, com o aumento da temperatura de queima. A exceção é para a cerâmica com $4 \%$ de coque, que apresenta uma redução da Rc a $1050{ }^{\circ} \mathrm{C}$ em comparação com a temperatura de $850{ }^{\circ} \mathrm{C}$. Na temperatura de $850{ }^{\circ} \mathrm{C}$ praticamente não ocorreu variação significativa da Rc da cerâmica com incorporação de coque de até $2 \%$. Já com $4 \%$ de incorporação o valor obtido de Rc é cerca de $44 \%$ superior ao valor obtido para a argila pura, $0 \%$ de coque. Para entender este comportamento é preciso mencionar que dois fenômenos antagônicos ocorrem simultaneamente com a queima de coque. Enquanto que o calor produzido pela combustão do carbono e dos hidrocarbonetos possibilita uma melhor consolidação das partículas, a porosidade gerada pode reduzir a resistência mecânica. O resultado final vai depender do efeito destes fenômenos no tamanho, geometria e localização dos defeitos na cerâmica. Por outro lado, a $1050{ }^{\circ} \mathrm{C}$, temperatura na qual as argilas cauliníticas apresentam uma elevada formação de fase líquida [11], a

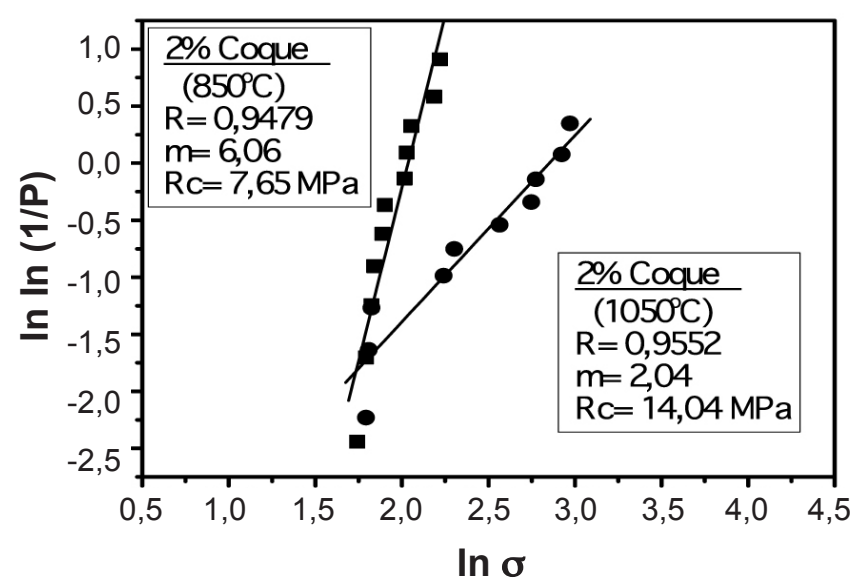

Figura 7: Diagrama de Weibull da composição com $2 \%$ em peso de coque de petróleo.

[Figure 7: Weibull diagram of the composition with 2wt.\% of petroleum coke.]

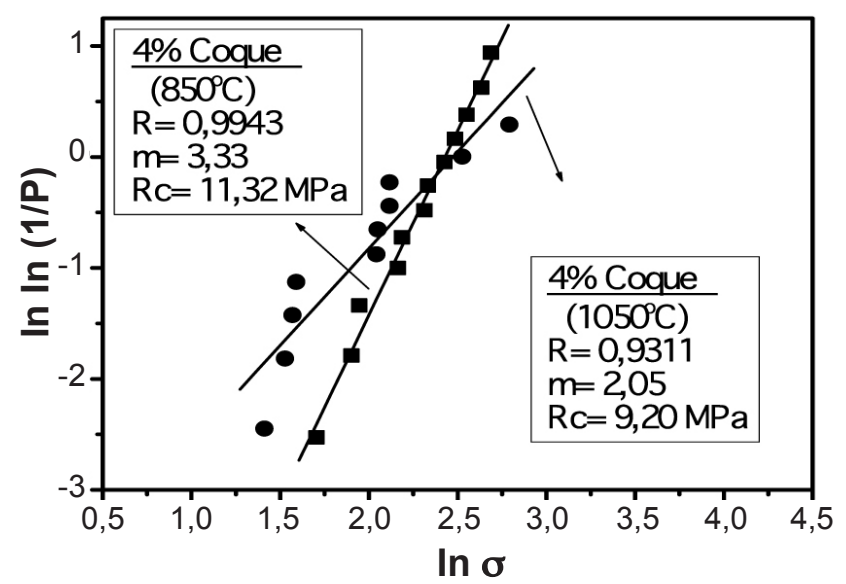

Figura 8: Diagrama de Weibull da composição com $4 \%$ em peso de coque de petróleo.

[Figure 8: Weibull diagram of the composition with 4wt.\% of petroleum coke.]

porosidade proveniente da combustão do resíduo parece ser predominante sobre a consolidação das partículas devido ao calor gerado pelo resíduo, pois ocorre uma redução brusca na Rc da massa argilosa pura, $0 \%$ de coque. Nota-se também que o coque de petróleo interfere significativamente na dispersão dos dados da resistência mecânica da cerâmica. A massa argilosa pura, apresenta o módulo de Weibull de 9,51 e 8,52 para as temperaturas de 850 e $1050{ }^{\circ} \mathrm{C}$, respectivamente. Com a incorporação de coque o valor de $\mathrm{m}$ é reduzido, sobretudo, a $1050{ }^{\circ} \mathrm{C}$. Este comportamento pode ser atribuído aos defeitos introduzidos na cerâmica pelo coque como porosidade e inclusões, aumentando a possibilidade de dispersão de dados.

As Figs. 9 e 10 apresentam as micrografias obtidas por microscopia óptica das cerâmicas queimadas sem e com $4 \%$ de coque, respectivamente. Notam-se trincas de conformação em ambas as cerâmicas e partículas de quartzo, indicadas por setas. As trincas nas cerâmicas são provenientes da relaxação elástica do material após a saída do molde do dispositivo de extrusão. Isto pode ser 

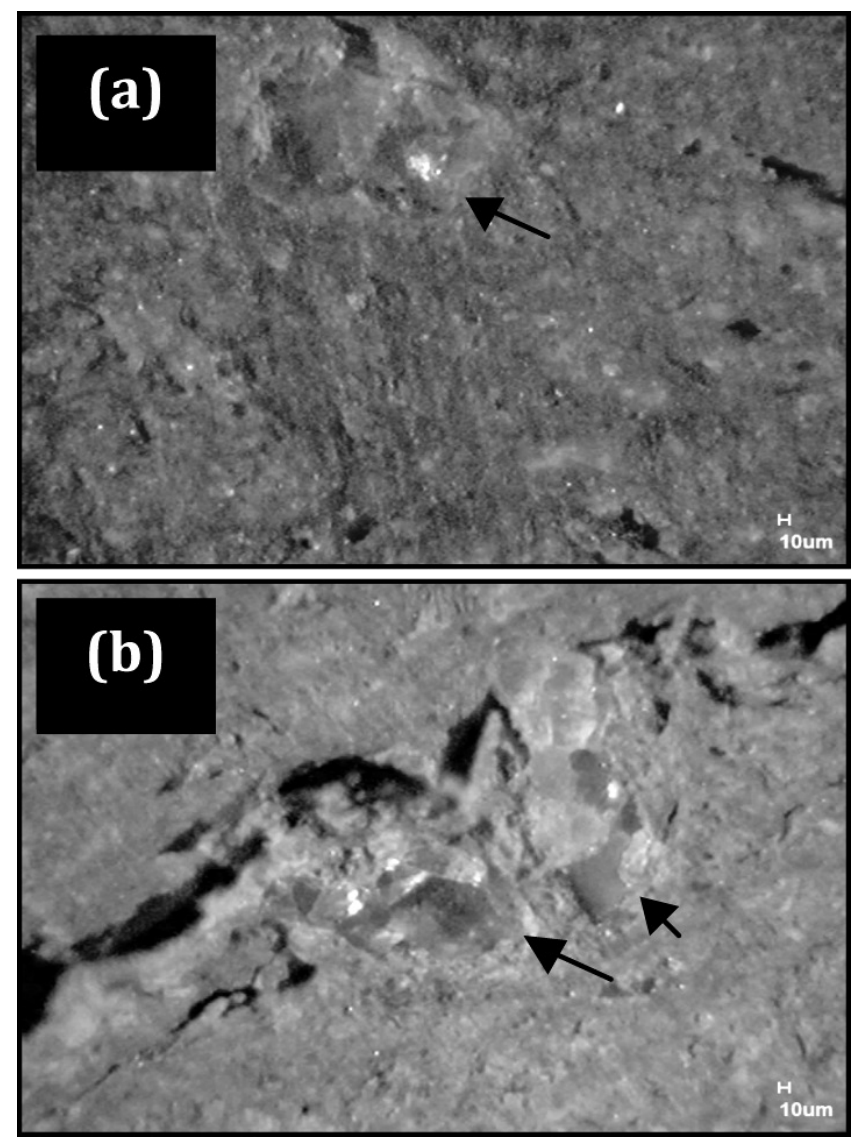

Figura 9: Micrografias de microscopia óptica da cerâmica sem coque de petróleo queimada a $850{ }^{\circ} \mathrm{C}$ (a) e $1050{ }^{\circ} \mathrm{C}$ (b).

[Figure 9: OM micrograph of the composition without petroleum coke fired at $850{ }^{\circ} \mathrm{C}(\mathrm{a})$ and $1050{ }^{\circ} \mathrm{C}(\mathrm{b})$.]

evitado alterando alguns parâmetros do dispositivo extrusor, como por exemplo, sua angulação em direção à boquilha.

A micrografia da Fig. 10a, cerâmica com $4 \%$ de coque queimada a $850{ }^{\circ} \mathrm{C}$, apresenta uma coloração mais acinzentada em relação às demais. Isto pode ser atribuído à combustão do coque com liberação de $\mathrm{CO}_{2}$, que acarreta uma atmosfera redutora no interior da cerâmica, alterando sua coloração. Já a $1050{ }^{\circ} \mathrm{C}$, Fig. 10b, nota-se uma coloração mais avermelhada, indicando que em temperaturas mais elevadas, a atmosfera volta a ser oxidante. As partículas pretas observadas na Fig. 10a são atribuídas a impurezas de compostos de Fe no resíduo.

\section{Considerações sobre o consumo de energia}

Um forno tipo garrafão, por exemplo, necessita de $900.000 \mathrm{kcal}$ para queimar 1 ton de argila [12]. Isto corresponde a uma eficiência de $30 \%$, já que teoricamente são necessárias $265.000 \mathrm{kcal}$ para queimar 1 ton de argila. A incorporação de $1 \%$ em peso de coque na argila gera uma energia adicional de aproximadamente $94.000 \mathrm{kcal}$, de acordo com o poder calorífico inferior apresentado na Tabela I. Portanto, a economia de energia propiciada pela incorporação de $1 \%$ de coque é de $\sim 10$ a $11 \%$. Isto
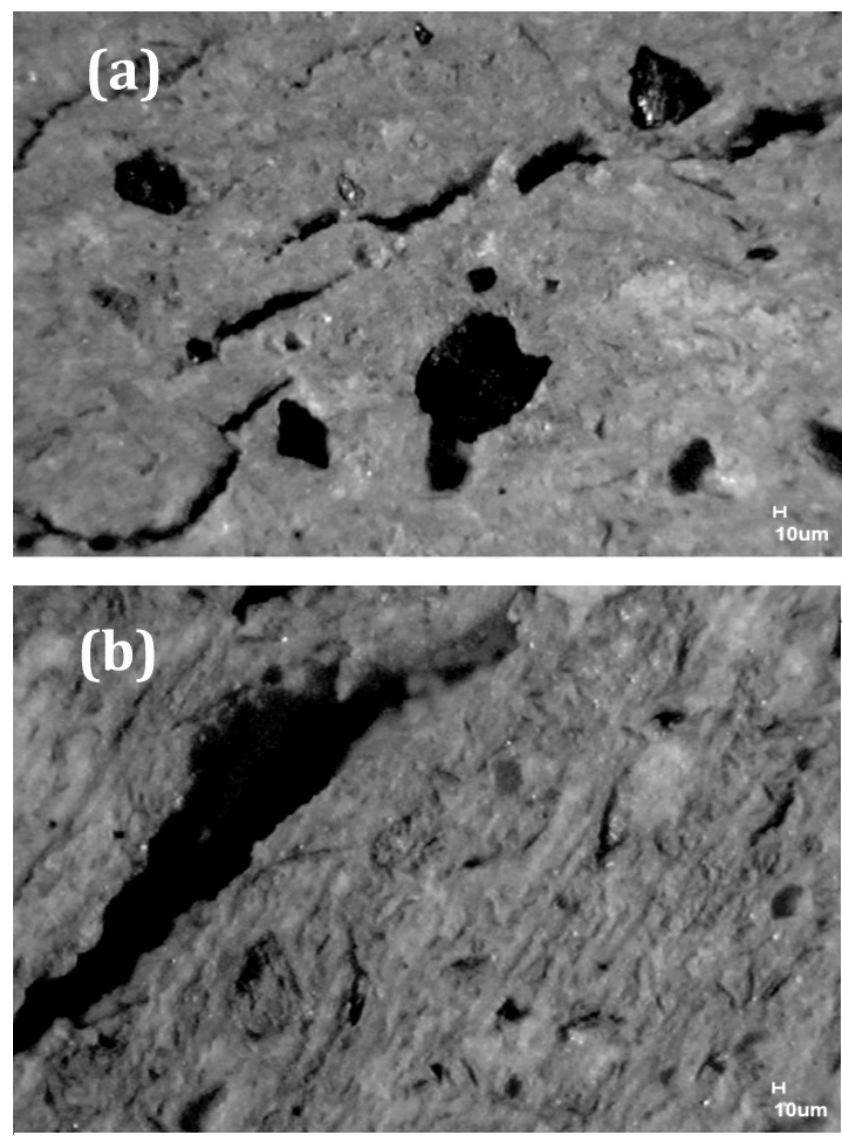

Figura 10: Micrografias de microscopia óptica da cerâmica com $4 \%$ de coque de petróleo queimada a $850^{\circ} \mathrm{C}$ (a) e $1050{ }^{\circ} \mathrm{C}$ (b).

[Figure 10: Optical microscopy micrograph of the composition with $4 \%$ of petroleum coke fired at $850{ }^{\circ} \mathrm{C}($ a $)$ and $\left.1050{ }^{\circ} \mathrm{C}(\mathrm{b}).\right]$

corresponde a $36 \mathrm{~kg}$ de lenha, por exemplo, considerando um poder calorífico de $2.600 \mathrm{kcal} / \mathrm{kg}$.

\section{CONCLUSÕES}

O coque de petróleo investigado neste trabalho apresenta uma granulometria apropriada para incorporação em cerâmica vermelha. O elevado poder calorífico pode possibilitar uma economia significativa de combustível na etapa de queima. A incorporação de coque de petróleo tende a aumentar a absorção de água da cerâmica argilosa. Já a resistência mecânica não sofreu alteração significativa com incorporações de até $2 \%$ a $850^{\circ} \mathrm{C}$. Observou-se até um incremento significativo da resistência mecânica com $4 \%$ de incorporação. A $1050{ }^{\circ} \mathrm{C}$ o coque de petróleo reduziu significativamente a resistência mecânica da cerâmica argilosa. Os defeitos acarretados pela combustão do resíduo interferem mais na resistência mecânica da cerâmica quando os mecanismos de sinterização, sobretudo formação de fase líquida, são mais pronunciados. Desta forma, o efeito benéfico do coque, economia energética, deve ser aproveitado com incorporações em quantidades a $\sim 1 \%$ em peso nas temperaturas usuais de queima da cerâmica vermelha, ou seja, inferiores a $1000{ }^{\circ} \mathrm{C}$. 


\section{AGRADECIMENTOS}

À FAPERJ, Proc. E-26/103.023/2008, e ao CNPq, Proc. 306027/2008-9.

\section{REFERÊNCIAS}

[1] D. V.Ribeiro,M.R.Morelli, Resíduos sólidos - problema ou oportunidade?, Ed. Interciência, Rio de Janeiro, RJ (2009) 3.

[2] M. Dondi, M. Marsigli, B. Fabri, Tile \& Brick Int. 13, 3 (1997) 218-225.

[3] M. Dondi, M. Marsigli, B. Fabri, Tile \& Brick Int. 13, 4 (1997) 302-308.

[4] C. M. F. Vieira, S. N. Monteiro, Matéria 14, 3(2009), 881-905.

[5] A. Carinni, G. Trondodi, A. Zani, Ind. Ital. Laterizi 1 (1987) 9-15.
[6] Associação Brasileira de Normas Técnicas - ABNT, Determinação da análise granulométrica de solos, NBR 7181, Rio de Janeiro, RJ (1984).

[7] American Society for Testing and Materials - ASTM, Water absorption, bulk density, apparent porosity, and apparent specific gravity of fired whiteware products, C 37372, EUA (1972).

[8] American Society for Testing and Materials - ASTM, Flexural properties of ceramic whiteware materials, C67477, EUA (1977)

[9] A. R. M. Junior, E. D. Zanotto, Cerâmica 38, 253 (1992) 7-11.

[10] M. Wissler, J. Power Sources 156 (2006) 142-150.

[11] S. N. Monteiro, C. M. F. Vieira, Appl. Clay Sci. 27, 3-4 (2004) 229-234.

[12] E. Más, Qualidade e tecnologia em cerâmica vermelha, Ap. 4. A queima, os combustíveis, Ed. Pólo Prod. Ltda. (2002) p. 42.

(Rec. 26/05/2010, Rev.07/07/2010, Ac. 14/07/2010) 